\title{
"Let's Just Stop and Take a Breath": A Community-Driven Approach to Mindfulness Practice in a High Poverty Elementary School
}

Shana Haines, Kelly Clark/Keefe, Alan Tinkler, Alyssa Kotsiopoulos, Cynthia Gerstl-Pepin, Katharine G. Shepherd, Haley Woodside-Jiron, and Morgan Milhomens

\begin{abstract}
This case study describes how a high-poverty, linguistically and culturally diverse elementary school came to embed mindfulness in its curriculum and what adults perceived to be the outcomes of the program on students' well-being. This qualitative case study is based on 25 interviews with teachers, administrators, and community members; classroom observations; and relevant documents. Participants indicated that practicing mindfulness improved student well-being through greater self-awareness and increased ability to articulate their emotions and needs, select strategies to self-regulate, and generalize their practice of mindfulness to out-of-school settings. Implications for practice and research are discussed.

\section{"Let's Just Stop and Take a Breath": A Community-Driven Approach to Mindfulness Practice in a High Poverty Elementary School}

More than 45 years ago, Paulo Freire (1970) argued for a dialectic that could help students "develop their power to perceive critically the way they exist in the world with which and in which they find themselves" (p. 83). School-based mindfulness can be one powerful way to promote the simultaneous dialectic that Freire and his contemporaries promote, whereby participants practice a type of "close-in" or bodily focused well-being alongside a "wide-open" critical thinking perspective, including a focus on academic success and the dynamics of the broader classroom, school, and community experience. Systematic approaches like The Whole School, Whole Community, Whole Child Model (Lewallen, Hunt, Potts-Datema, Zaza, \& Giles, 2015) to health and learning underscore, among other things, the importance of fostering social, emotional, and academic growth within schools, communities, and families. Central to this framework is the connection between education and health for students, who can benefit from improving their emotional well-being (Jennings \& Greenberg, 2009; Richards, 2012). Given that stress and anxiety can have a negative impact on classroom climate, creating educational spaces conducive to learning requires attention to be given to social and emotional learning as well as academic achievement (Gueldner \& Feuerborn, 2016).

This integrative focus is particularly important given that nearly a third of the adolescent population qualifies as having an anxiety disorder (Merikangas et al., 2010). Schools with high percentages of lowincome students, English Language Learners, and students with identified disabilities face intense 
pressure (Linn, Baker, \& Betebenner, 2002), and these schools often experience high teacher turnover due to high levels of stress associated with working conditions (Johnson, Kraft, \& Papay, 2012). Substantial evidence suggests that poverty has an adverse effect on student achievement (Lacour \& Tissington, 2011), health, and well-being. Social inequities such as a lack of access to jobs with livable wages, nutritional food, quality early childhood care, stable and affordable housing, and quality health care can create an unhealthy environment (Evans, 2004; Komro, Flay, \& Biglan, 2011). Mindfulness practice has been suggested as one way to proactively cultivate health and well-being, thereby alleviating stress and anxiety (Beauchemin, Hutchins, \& Patterson, 2008; Broderick \& Metz, 2009; Gould, Dariotis, Mendelson, \& Greenberg, 2012; Meiklejohn et al., 2012; Napoli, Krech, \& Holley, 2005; Sibinga et al., 2011) and counteracting the negative effects of childhood poverty on physical and mental health.

In this paper, we provide a case study of one high-poverty elementary school's efforts to integrate regular mindfulness practices across all K-5 classrooms. We describe the process of implementation and explore what we have come to understand through teacher and administrator interviews and classroom observations have been the effects of a community-driven school-based mindfulness practice on students' well-being and engagement in learning. In the paragraphs below, preceding a discussion of the study's methodology, we sketch the accelerating landscape of research on school-based mindfulness, placing emphasis on recent studies that report on the influence of these practices for student health, wellbeing, and engagement in learning. We then describe the case study's methodology before transitioning to our findings and a discussion of the implications of this work.

The groundswell of interest in the study of school-based mindfulness (Feagans Gould, Dariotis, Greenberg, \& Mendelson, 2016; Felver, Celis-de Hoyos, Tezanos, \& Singh, 2016; Rempel, 2012) is testimony to the need for work focused on fostering health and well-being in education. Recent research suggests that practicing mindfulness can assist students in taking control of their behavior and learning by developing their self-awareness and strengthening their self-regulatory skills (e.g., Felver et al., 2016). Specifically, students who participate in mindfulness interventions show reductions in stress and anxiety levels and improvements in emotional regulation (Beauchemin et al., 2008; Broderick \& Metz, 2009; Gould et al., 2012; Napoli et al., 2005; Sibinga et al., 2011). Practicing mindfulness can also promote students' development of social skills and empathy (Beauchemin et al., 2008; Black \& Fernando, 2013; Schonert-Reichl et al., 2015). Recent research also shows that mindfulness practice can affect student academic achievement (Bakosh, Snow, Tobias, Houlihan, \& Barbosa-Leiker, 2016; Flook, Goldberg, Pinger, Bonus, \& Davidson 2013; Singh et al., 2016) and executive functioning (Flook et al., 2010). Taken together, evidence that school-based mindfulness practices have the ability to influence self-regulation, reduce student stress and anxiety, assist in the development of pro-social skills, and promote academic achievement has fueled (a) the study of mindfulness' effects for student health and well-being and (b) the techniques and with which populations of children and youth these techniques are viewed as most advantageous (Rempel, 2012).

While previous studies have reported that practicing mindfulness has positive effects on student health and well-being, our study is distinctive because it also documents the organic implementation of a community-driven school-based mindfulness practice. Specifically, our study illustrates how a diverse, 
high poverty, urban elementary school community in the Northeastern United States implemented a school-wide mindfulness practice. The following research questions guided this study: How and why did George Washington Elementary School (GWE; a pseudonym) implement a school-wide mindfulness initiative, and what were the perceived effects of the initiative on student well-being and learning?

\section{Methodology}

Our research was initiated when a staff member at a local center promoting mindful learning, the Center for Mindful Learning $(\mathrm{CML})$, contacted our research team to discern interest in investigating their work in a local community and school district. While the larger CML project involved supporting a city-wide approach of advancing mindfulness practices across the community, our research team decided that the first stage in the research project would be to document CML's initial work in the city's elementary school, which was the precursor to the city-wide focus on mindfulness training. In keeping with CML's collaborative approach, we designed a community-based descriptive case study using a holistic singlecase design (Yin, 2009) to document the implementation of mindfulness practice at GWE. Holistic singlecase design case study is appropriate for a case study with a single unit of analysis (Yin, 2009); in this case, the unit of analysis was the elementary school. Our research team consisted of six faculty members in a college of education and social services and two undergraduate students. This research was our team's first exposure to the school's mindfulness initiative.

\section{Data Collection}

Data collection consisted of three data gathering techniques: semi-structured interviews, classroom observations, and document review. All participants granted informed consent prior to interviews and observations.

Interviews. We utilized a semi-structured protocol to elicit the story of mindfulness practice at GWE from each interviewee's perspective (Patton, 2015). Most questions were open-ended (e.g., "Tell us about when you started using mindfulness practice in your teaching and why"), though some were geared towards more specific information (e.g., "How many years have you been teaching?"). We used followup probes to draw out more information as participants spoke (Yin, 2011). Interviews with educators lasted 30 minutes each while interviews with other participants lasted between one and two hours. Eighty-five percent of all interviews were conducted by two researchers, while the remaining 15\% were conducted by one researcher. Each researcher completed analytic memos (Miles, Huberman, \& Saldaña, 2014) immediately following the interviews, which included questions about the salient aspects of the interview, surprising information, and follow-up questions for future interviews.

We employed purposeful sampling (Patton, 2015) to identify all teachers and other school and community members who were considered key players in the school mindfulness initiative. The interviewees included the school's principal, two parents who were instrumental in bringing mindfulness practice to GWE, 20 educators at GWE (representing 90\% of classroom teachers, one special 
educator, and the guidance counselor), CML staff, the school district's Wellness Coordinator, and the Superintendent of the district.

Classroom observations. We also conducted observations of 19 (out of 21, or 90\%) classrooms as they implemented their structured mindfulness practice. In some cases, observations included classroom activities conducted immediately before and after mindfulness practice. Observations ranged from 15 to 35 minutes and were conducted by one $(n=14)$ or two $(n=5)$ researchers. During these observations and immediately following them, we took notes on the objects being used in mindfulness practice (e.g., cushions, chimes), what we noticed about the organization of space and time, and how student and teacher bodies were acting and interacting in the classroom environment (Bresler, 2004). After each observation, the team of observers met to discuss what they heard, saw, and sensed in the classroom spaces and to list follow-up questions to be asked at subsequent interviews.

Document review. We collected and reviewed a wide variety of relevant documents as part of the case study in order to triangulate the data (Patton, 2015). These included numerous websites, newsletters, online materials (including the CML training program), and other school materials related to understanding the history and current status of mindfulness practice at GWE.

\section{Data Analysis}

We employed a constant-comparative (Glaser \& Strauss, 1967) method of data analysis, meaning that we formed questions for subsequent interviews and observations while we wrote and discussed our analytic memos from the interviews, observations, and documents. After removing identifying information from transcripts and checking them for accuracy, at least three researchers read and opencoded (Corbin \& Strauss, 1990) the first 22 transcripts using Microsoft Word. The first author was one of the readers and coders of all transcripts. We then met to discuss these first-cycle codes (Miles et al., 2014) and discern primary codes that categorized all the codes. We entered the interview transcripts into Dedoose, an online qualitative analysis software program that enables collaborative coding, and two authors coded all transcripts for the parent codes. Next, we came up with sub-codes from the data sorted into primary codes and discussed the definitions of these codes: a process which established the trustworthiness of the codes and collaborative coding process (Noble \& Smith, 2015). To check the credibility of these themes, we confirmed them with subsequent interviewees as a form of member checking (Patton, 2015). After the initial round of interviews, observations, and coding, we also shared the main themes with the school principal and two additional key informants, the Wellness Coordinator and the Superintendent, whom we had not yet interviewed. These three participants corroborated the themes that had emerged, provided more data to support them, and offered new data that added greater depth to the case study. 


\section{Findings}

In this section, we present the history of mindfulness practice at GWE and the current practice as observed by our research team and described by participants. We then focus on conditions necessary for successful practice and detail the effects of mindfulness practice on student well-being. Those effects include the ability to identify and discuss emotions and needs, choose strategies to self-regulate and sustain engagement, use mindfulness practice outside of school, and exhibit increased self-awareness.

\section{School Context}

GWE serves approximately 400 PreK through fifth grade students. Situated in an otherwise culturally and racially homogenous state in the northeastern United States, the student population at GWE is quite diverse due to the community's status as a refugee resettlement area, with 31 languages spoken and 26 nationalities represented. Approximately $75 \%$ of students qualify for free or reduced-priced meals, $18 \%$ have an Individual Education Plan, and about 35\% of students receive English as a second language services. In 2013, the school did not achieve the AYP indicators under NCLB for reading and mathematics.

\section{Crafting a School-Wide Commitment to Mindfulness: Attending to Focused Relaxation}

According to the principal, the 2012 school year was "a horrendous year; one that you just block out for the rest of your life so that you can move forward." She reported that issues with student behavior built up and led to student and teacher frustration and burnout. These behavior issues were "tipping the balance of the whole building," and school personnel were at a loss regarding how to get things back on track. Recognizing the need for change due to teacher burnout and student behavior, the principal met with the school leadership team in 2013 to address the acknowledged problem of student behavior.

Meanwhile, two parents—one a special educator who teaches in a different district; the other, a Pilates and yoga instructor-advocated for a change based on what they had witnessed in their own children's classrooms. These parents volunteered their time to teach mindfulness, meditation, and yoga to students in any class while also talking with the principal about positive behavior supports, social thinking curricula focused on developing social competencies related to behavior, and the importance of common language. Some teachers accepted these parents' offer to practice mindfulness and yoga in their classrooms.

Witnessing increased self-awareness among students participating in these informal mindfulness practices, the school principal encouraged more widespread use of mindfulness and yoga practices in the classroom. The principal worked to increase the consistency of language used to discuss behavior by implementing the social thinking curriculum, SuperFlex, designed to help students adjust their behavior in order to lead more meaningful, happier lives (Madrigal \& Winner, 2008). While this was helpful, the principal, in conversations with her leadership team and other staff, did not feel that it was sufficient to address the needs of teachers and students. 
At the start of the summer of 2013, the leadership team decided to adopt the CML online mindfulness program, a program designed to introduce mindfulness across multiple classrooms, because it could be implemented without extensive teacher training. CML trained seven interested teachers and school leaders to use their online program over the course of two professional development days. All teachers were required to attend one hour of the training, during which CML staff led a mindfulness activity for school personnel and explained how the program worked in classrooms. After this school-wide training, seven additional teachers decided to participate and were given access to the online program. By the end of the first year, all teachers asked for and were given access to the CML site.

While some teachers originally conceived the two as separate initiatives, the principal and other adopters fostered the understanding that social thinking was the overarching "umbrella" of behavior appropriate for social situations (including school) with mindfulness strategies (e.g., deep breathing, counting to ten, turtle time, taking a walk) as "specific tools" within the bigger umbrella. The school leadership team hoped that aligning these complementary initiatives would provide students and teachers with a coherent, transparent, and adaptive curriculum focused on improving self-awareness and self-regulation in relation to the broader classroom and school community.

According to teachers' self-report of their usage of the online program when mindfulness practice was first introduced in 2013, 75\% of teachers participating in any form of mindfulness (14 teachers) were exclusively using the online program. The online program centered on the concept of practicing focused relaxation. Over the following two years, however, teachers grew increasingly comfortable with the program and broadened their understanding of mindfulness, which resulted in many teachers branching out on their own and adapting the curriculum to suit their teaching style. At the time of data collection (2015), the majority of participants used focused relaxation, the fundamental tenet behind the online program, as their framework while they crafted their own activities for mindfulness practice. In fact, at the time of data collection, $45 \%$ of teachers reported using their own practices at least $50 \%$ of the time, $35 \%$ of teachers reported using an entirely independent mindfulness curriculum, and the remaining $20 \%$ reported using only CML's online program. Our observations of the classrooms revealed that mindfulness practices looked quite different, depending on teachers' reliance on $\mathrm{CML}^{\prime} \mathrm{s}$ online program compared to practices that took a more independent approach. Across the school, mindfulness practice ranged from student-led deep breathing exercises to online-led visualization stories to Zumba routines and yoga poses.

For example, in a fourth grade classroom where the teacher relied solely on the CML program, students began mindfulness practice sitting at their desks in a darkened room, facing an interactive whiteboard displaying a simple drawing of a tree. The student leader for the day started the three-minute program by clicking on the arrow. Students were guided by a male voice through an eyes-closed visualization scenario. The teacher sat in the back of the room monitoring student behavior and partially participating (with open eyes) in the mindfulness exercise. Some students closed their eyes and seemed to participate in the activity, but others did not close their eyes or engage in the deep breathing activity. At the end of the program, a student leader was prompted by the program to answer (on the interactive whiteboard) three questions centered on their ability to focus and remain mindful during the program. 
On the other end of the continuum, in a classroom where the teacher no longer used the CML online program, the mindfulness practice looked markedly different. Students eagerly formed a circle on the rug in a quiet, dimly lit corner of the room to begin their mindfulness practice. The classroom teacher, enthusiastic yet serene, pulled out a large jar filled with water and colored glitter. She then asked students, "What is a worry you want to release from your mind today?" The teacher explained that the glitter in this jar represented the class' worries, troubles, and negative feelings. After the teacher shook the jar, the glitter settled to the bottom, representing the release of these stressful emotions. Simultaneously, students as well as their teacher closed their eyes while deeply breathing in and out. The teacher then led students in a discussion about ways they could calm down and let go of negative feelings as they emerge; the last few sparkles settled to the bottom of the jar. Students excitedly offered answers such as, "I close my eyes and breathe in and out very slowly." This particular session ended by making the sound of "om" together as a class before the students' transition to their lunch period.

While there was generally a scheduled time for mindfulness practice in each class, the practice of being mindful was often reinforced throughout the school day during situations where mindfulness could be particularly beneficial (e.g., impulsive reactionary behavior). Regarding classroom environment, many classrooms were furnished with materials to facilitate mindfulness (e.g., a peace corner with coloring books and utensils, chimes, and bells; a dedicated computer to access mindfulness practice sites).

Teachers reported different schedules for structured mindfulness practice in their classrooms. Just over two-thirds of the teachers reported structuring the mindful practice at a particular time of day, including the beginning of the day, prior to math class, or before/after recess. The remaining teachers reported practicing mindfulness at different times throughout the week and adjusting the time according to students' needs, as one teacher explained:

... I just felt like my class needed that time together - that togetherness feeling that mindfulness creates before recess... that talk of empathy comes out, that talk of being mindful of what's going on around you at recess, to try to help some of those recess behaviors...

\section{Mindfulness Practice's Effects on Student Well-Being}

Participants described numerous benefits of school-wide mindfulness practices on students' health and well-being. Overall, participants reported that once students appreciated the importance of practicing mindfulness, positive effects included increased self-awareness and increased ability to identify and discuss emotions and needs, choose strategies to self-regulate and sustain engagement, and use mindfulness practice outside of school.

Conditions for practice. Participants reported that practicing mindfulness made more of an impact on students' well-being when certain conditions were met.

First, participants reported that it takes time to learn to use mindfulness. The guidance counselor, who works with classrooms on a rotating schedule, for instance, commented: 
The kids where they haven't practiced it... It's kind of a silly time. It's uncomfortable to... know that other people are sitting quietly around you and that you're sharing a space but you're not talking. That seems weird for a lot of kids so I can tell for sure if a kid has been practicing it or not.

Participants also spoke about the importance of practicing mindfulness proactively, when students are not in an elevated state. The principal stated that she and teachers have discussed "that [students] practice all these strategies when it's not a high-stress time so then they can access these strategies during a highstress time." A teacher addressed the importance of practicing when not in an elevated state, claiming it helped the students build "muscle memory. The more they practiced together... when I would say, 'How about you take a deep breath right now and see if that helps?' they knew what that meant, and it wasn't just me saying RELAX." In addition to practicing proactively, participants recognized the importance of establishing a routine and norms around mindfulness practice.

Not surprisingly, regular and proactive mindfulness practice was seen as most helpful for those students who "bought in." Still, for those students who were not certain that the practice would help them or did not see the need for help, participants spoke of different engagement strategies that they used with persistence to expand meaningful participation. It was interesting for us to find that participants did not have any common descriptors for students who participated avidly and those who did not, suggesting that teachers and administrators were able to suspend judgment about what engagement in mindful activity meant or looked like for individual students. One participant, for instance, mentioned that she was surprised to see "really big, tough, macho guys... sit down and just shut their eyes and breathe. It's really neat," while another described that "one [student who] is considered non-English—she knows about maybe 12 words of English—can lead us in the breathing."

We found that conditions for school-based mindfulness practice in as diverse and inclusive of a place as GWE require the availability and flexibility of various tools and techniques. Teachers adjusted their motivating techniques since each class had different levels of participation. One teacher explained:

And that class last year was just so like... 18 sponges ready to take it in. This year I've got a different demeanor in the room... At the beginning of the year, it was unfortunate but I almost had to bribe them a little bit to buy into it... But the classrooms are so utterly just imbalanced as far as personalities and dynamics and stuff that kids were just like, quiet time and having their head down felt very nerve wracking. So I've noticed a change in that over the course of the year where kids are like, "Cool, time to put my head down." Like, "I can do this."

This teacher found that once students became accustomed to mindfulness practice, they "bought in" and benefitted from it. Some teachers underscored the importance of validating students' choice to be involved or not to be involved, which in itself underscores the quality of nonjudgmental practice and promotes self-regulation and buy-in.

Benefits of practice. Participants attributed practicing mindfulness with numerous benefits to the students' well-being and engagement in learning. The benefits included increased self-awareness, awareness of others, self-regulation, communication about states of mind and needs, and use of strategies outside of the classroom. 
One of the benefits widely acknowledged by participants was students' increased ability to identify and articulate their needs through greater self-awareness. Students' ability to think about what is happening in their own bodies is critical to them being able to deal with their needs appropriately:

So they come back from that wild and chaotic time [the lunchroom] and they're so unaware of themselves in that space because there's so much going on... It's over stimulating... And that's what I try to get them to do: focus on whether or not you are feeling relaxed...

Participants recognized that this self-awareness enabled students to attune to signs from their body independently of teachers; as one participant noted:

Particularly in 4th grade, it seems important for them to start becoming aware of when they're feeling tense, when they're feeling whatever [because] they're starting to get to a place in their educational life where adults are not going to be policing them as often, and it's really important to be able to know yourself and know when you're feeling tense, know when you're feeling calm... so that you can deal with it appropriately.

As students became accustomed to identifying their needs, they could select and execute strategies to regulate their thoughts and behavior accordingly: "It's not just an adult saying 'that's unexpected, that you're making a weird noise right now'... Instead, someone might say to himself, 'Why am I making the weird noise? I'm feeling anxious, okay, now I need to pick a strategy.'" One participant explained that when students are upset or struggling, they are able to identify strategies they can employ to self-regulate: "I can listen to my breath, I can do a belly breath, I can do a palm press, I can listen to the noises in the room. So they've got this big toolbox now that they've practiced,"

Importantly, we found that participants discussed how, once their students practice mindfulness, teachers were less involved in helping students regulate their behavior and emotions: "they're in charge of their selves more, on how to get calmed down. And it also really helps them with how much attention they can spend and how long they can spend at something when they're learning." One teacher explained how students had "glass man moments' where they had really big reactions to small problems" in the past. She continued: "So, by using the mindfulness and having that practice every day...they were able to call upon those strategies that they used during the different time of the day when they were having a big reaction." In other words, students who struggled with learning self-awareness skills benefited when teachers modified their mindfulness practice and provided additional supports that helped students engage with them.

In addition to increased self-awareness, participants reported that the school-wide initiative helped students talk about their needs and strategies using "the terminology_oh, we need to be mindful right now." This terminology included language from the SuperFlex curriculum (e.g., "Glass Man," "Mean Jean," "Rock Brain"), which participants wove together with the names of mindfulness strategies and somatic symptoms. One teacher explained:

[Mean Jean] is from Social Thinking. She's just a gal who's really mean. She could go off and say, "I just hate you. I just hate your sweater," or something like that. And she gets in that mode and I 
say, "what do you think you can do to get out of that mode?" "Well, I could blow like the wind and just sit and think. I could blow out the candles. I could starfish breathe. I could palm press."

Students verbalize aloud what they are doing using this terminology through self-talk ("Oh, okay, I'm going to take a deep breath") which, according to participants, helps them and other students utilize those strategies. Using self-talk is especially powerful for younger students, as explained by one teacher:

It's a lot harder for [first graders] to say it in their head than it is to say it out loud. So we practice that a lot... And we do a lot of just quick turn to your neighbor and say, "you did a great job" or turn to your neighbor and say, "I can do this." I mean something like that is so simple but it's been really positive and is changing the community in my classroom to be able to be a positive place of teamwork where mistakes are okay, where that environment of learning is a positive and supportive place.

Many participants also described students' ability to be more aware of their reactions to other people's behavior as an important aspect of improved self-awareness. Identifying what was bothering them and using mindfulness strategies alleviated negative behavior by shifting the perceived locus of tension and stress from being purely internal to acknowledging external triggers and therefore mindfully responding to others behaviors. One teacher shared an example of this:

A student shared with me that 'so-and-so bumped into me and I took a couple of deep breaths and I was able to walk away, have fun and not push them back.' Wow, that's amazing. Like you felt the urge to push someone and you took some deep breaths and you chose not to? (Interview 9).

Another teacher noticed that, when there were outbursts in the classroom, because the students had learned how to relax in times of stress and trust that they would be safe, "...the kids are able to stay focused on what they're doing and get their work done. They [think] (teacher) will take care of this, we just need to be and just relax."

The benefits were not simply related to inter- and intra-personal skills. Participants also indicated how increased self-awareness affected students' (and teachers') ability to see the connection between personal health, well-being, and intellectual acumen, namely through increasing student metacognition of their learning strategies and needs. One teacher shared, "They know they're supposed to be thinking about how their brain works and what [their] brain is figuring out, and I think mindfulness just goes hand in hand with that. It's understanding how your brain works." This metacognition manifested itself during and before many high-pressure activities, including the standardized tests:

I saw kids with S-BAC [statewide testing] turn-we call it Apples Up because they put their [Apple computer] screen down-and just putting their head down for a few minutes... Or, I watched a kid last year turn his test over, put his pencil down and just sit there like this. And then a minute or two later, he picked up his pencil, he opened it back up and he kept going.

Participants also spoke about how students with significant anxiety benefitted from practicing mindfulness. One teacher explained: 
He would scream and - I mean high-pitched screams, run around the room, throw things, destroy... now I will notice him at times when he's getting a little bit anxious or upset about something, that he will just take a deep breath and he'll... [deep breath] close his eyes.

Others told us about the effects on students' well-being outside of school. One teacher summarized the importance of transferring mindfulness practice to home life: "A lot of them go home to some really stressful situations... They can't control the situation out there... Our own anchors help to work within traumatic situations... It gives them hope." Another teacher explained how she would ask students about how they used mindfulness over the weekend. She recounted how one student answered: "Well, my sister was hitting me with a book and I took a deep breath and then I went in and asked my mom for some help." Mindfulness supported interpersonal relationships, and supported students experiencing stress, including very high-risk, anxiety-producing situations. One participant shared this story of a student who was able to use mindfulness skills learned at school to self-regulate when his apartment went up in flames:

The family lost everything... In the past, he has been somewhat a little challenging, but he bought into it [mindfulness practice] right away. And he shared with the group at one point - he was like, when I was standing there watching my apartment go up in flames - because he came home to it - I didn't know where my mother and sister were and there was part of me that wondered if they were still inside. And he said, "All I could hear was fire engines, people yelling, like just chaos and everything. And I kind of closed my eyes and paid attention to all the sounds and I was breathing in and breathing out and I opened my eyes and, a few moments later, off the sidewalk come my mom and my sister." That was like my powerful one that the whole class was like - whoa.

Some teachers reported communicating clearly with their students' families about mindfulness practice in the classroom. A kindergarten teacher explained how she and her colleagues communicated with families:

And what we do is we have a kindergarten newsletter and it goes out and we donate one square about being mindful. What we're doing this month in mindfulness, we're learning to relax, we're learning to stay relaxed within our brain. In this lesson, we're learning to look for sounds; we're learning to hear the world around us. Every time that we do something different, we put it in the block and we tell parents a key idea of practice - to do some practice at home. So we're sending it home, too. And parents are really using it.

In addition to this formal communication, participants reported that parents were surprised to see their children using mindfulness at home and shared stories with teachers during parent/teacher conferences and other events. One mother was a little baffled by her son's use of mindfulness at home; the mother told the teacher that her son:

was really, really mad at his sister. He stormed out of the room. And I walked in his room and he was in his bed and he was just - he had his head really low and he was taking really deep breaths. I said, (Student) "are you all right?" He goes, "Yeah, I'm just breathing, mom. I'm just breathing." It's so great. It's just - it's so powerful that these kids are living in some pretty bad situations, that they have something that they can get control over their own presence, their own being, that's really positive for them. And they're experiencing it here and that whole connection. 
And now mom has those tools too of saying "oh, (Student) this would be a really good time to just take a break. Oh yeah, okay." And they have a little place [...] this take-a-break place. But it just gives the parents some tools, too.

\section{Discussion}

Our study illustrates how one diverse urban elementary school implemented a school-wide mindfulness practice and its effects on student health and well-being. Participants expressed that practicing mindfulness increased students' self-awareness, which helped them articulate their emotions and needs, often using commonly known language from the social thinking curriculum in place at GWE. Once able to identify their needs, students were able to choose from strategies they had learned through their proactive practice to self-regulate. Students were also able to control their reactionary behavior as well as focus on strategies to engage in their learning. Participants also expressed that many students had been using mindfulness strategies outside of school.

While there are numerous studies that show that practicing mindfulness has positive effects on student outcomes, this study is unique in that it describes the organic process of a community-driven and schoolwide implementation of mindfulness practice, resulting in adoption of mindfulness as a central, unifying practice. An interesting finding is that participants' thorough integration of the social thinking curriculum with their mindfulness practices productively bolstered the possibility for developing a more salient set of tools, including common language to be used for communicating both within and across the school and broader community. In addition, teachers used an online mindfulness program when starting their practice but, as they became more confident in their understanding of mindfulness practice, shifted to using other mindfulness-promoting activities. Mindfulness practice occurred regularly in the classrooms, but teachers, being mindful of their students' needs, introduced flexibility in the timing and nature of the practice in order to ensure its utility and success.

While this case study is not meant to be generalizable, we strove to include enough detail for readers to relate the findings to their own settings (Patton, 2015). The family- and community-driven mindfulness initiative studied serves as an innovative case study example for supporting health and well-being for students, especially those who attend high poverty elementary schools. Specifically, the study provides some direction for school administrators and educators hoping to increase student well-being through improved social emotional learning, engagement in learning, and school climate. First, a unique feature of GWE's implementation of mindfulness practices was the intentional blending of a social thinking curriculum with the more holistic approach offered through mindfulness practice, resulting in an alignment of initiatives and the potential for an integrated approach to change. This appears in contrast with initiatives focused only on curricular change or mindfulness. Future research might explore this blended approach in greater detail to further articulate its potential to expand students' growth and wellbeing. Second, implementation of mindfulness practices at GWE occurred through both a "top-down" and "bottom-up" approach to implementation that appeared to contribute to its success. The principal offered strong support of the initiative and provided opportunities for professional development; at the 
same time, she and the leadership team encouraged a flexible approach to implementation that resulted in a high level of adoption. Related to this, adoption of mindfulness practices at GWE came about in large part because of the leadership team's willingness to embrace family input and innovation, as well as larger support offered through the community as a whole. This holistic and community-focused approach to implementation is one that may be particularly important in a high-poverty community experiencing rapid social change. Finally, each of these implications should be of interest to educator preparation faculty who seek to prepare the next generation of teachers and administrators to creatively collaborate with community partners to ensure student well-being.

\section{Conclusion}

Health and learning are inextricably linked, and educational approaches aimed at fostering social, emotional, and academic growth within schools, communities, and families can improve student wellbeing (Jennings \& Greenberg, 2009; Lewallen et al., 2015; Richards, 2012). Especially in high-poverty schools, proactive approaches like the organic community-driven mindfulness implementation described in this article are critical to cultivating health and well-being, alleviating stress and anxiety (Beauchemin et al., 2008; Broderick \& Metz, 2009; Gould et al., 2012; Meiklejohn et al., 2012; Napoli et al., 2005; Sibinga et al., 2011), and counteracting the negative effects of childhood poverty on physical and mental health.

\section{References}

Bakosh. L. S., Snow, R. M., Tobias, J. M., Houlihan, J. L., \& Barbosa-Leiker, C. (2016). Maximizing mindful learning: Mindful awareness intervention improves elementary students' quarterly grades. Mindfulness, 7(1), 1-4.

Beauchemin, J., Hutchins, T. L., \& Patterson, F. (2008). Mindfulness meditation may lessen anxiety, promote social skills and improve academic performance amongst adolescents with learning difficulties. Complementary Health Practise Review, 13, 34-45.

Black, D., \& Fernando, R. (2014). Mindfulness training and classroom behavior among lower-income and ethnic minority elementary school children. Journal of Child \& Family Studies, 23(7), 1242-1246. doi:10.1007/s10826-013-9784-4

Bresler, L. (Ed.) (2004). Knowing bodies, moving minds. Boston: Springer Science+Business Media.

Broderick, P. C., \& Metz, S. (2009). Learning to BREATHE: A pilot trial of a mindfulness curriculum for adolescents. Advances in School Mental Health Promotion, 2(1), 35-45.

Corbin, J., \& Strauss, A. (1990). Grounded theory research: Procedures, canons, and evaluative criteria. Qualitative Sociology, 13(1), 3-21.

Evans, G. W. (2004). The environment of childhood poverty. American Psychologist, 59(2), 77-92. 
Feagans Gould, L., Dariotis, J. K., Greenberg, M. T., \& Mendelson, T. (2016). Assessing fidelity of implementation (foi) for school-based mindfulness and yoga interventions: A systematic review. Mindfulness, 7(1), 5-33. doi:10.1007/s12671-015-0395-6

Felver, J., Celis-de Hoyos, C. E., Tezanos, K., \& Singh, N. N. (2016). A systematic review of mindfulnessbased interventions for youth in school settings. Mindfulness, 7(1), 34-45. doi:10.1007/s12671-0150389-4

Flook, L., Goldberg, S. B., Pinger, L., Bonus, K., \& Davidson, R. J. (2013). Mindfulness for teachers: A pilot study to assess effects on stress, burnout, and teacher efficacy. Mind, Brain, and Education, 7(3), 182-195.

Flook, L., Smalley, A. L., Kitil, M. J., Galla, B. M., Locke, J., Ishijim, E., et al. (2010). Effects of mindful awareness practices on executive functions in elementary school children. Journal of Applied School Psychology, 26(1), 70-95. doi:10.1080/15377900903379125

Freire, P. (1970). Pedagogy of the oppressed. New York: Continuum.

Glaser, B. G., \& Strauss, A. L. (1967). The discovery of grounded theory: Strategies for qualitative research. Chicago: Aldine Publishing Company.

Gould, L., F., Dariotis, J.K., Mendelson, T., \& Greenberg, M. (2012). A school-based mindfulness intervention for urban youth: Exploring moderators of intervention effects. Journal of Community Psychology, 40(8), 968-982.

Gueldner, B. A., \& Feuerborn, L. L. (2016). Integrating mindfulness-based practices into social and emotional learning: A case application. Mindfulness, 7(1), 164-175.

Jennings, P. A., \& Greenberg, M. T. (2009). The prosocial classroom: Teacher social and emotional competence in relation to student and classroom outcomes. Review of Educational Research, 79, 491525. doi:10.3102/0034654308325693.

Johnson, S. M., Kraft, M. A., \& Papay, J. P. (2012). How context matters in high-need schools: The effects of teachers' working conditions on their professional satisfaction and their students' achievement. Teachers College Record, 114(10), 1-39.

Komro, K. A., Flay, B. R., \& Biglan, A. (2011). Creating nurturing environments: A science-based framework for promoting child health and development within high-poverty neighborhoods. Clinical Child and Family Psychology Review, 14(2), 111-134.

Lacour, M., \& Tissington, L. D. (2011). The effects of poverty on academic achievement. Educational Research and Reviews, 6(7), 522-527.

Lewallen, T. C., Hunt, H., Potts-Datema, W., Zaza, S., \& Giles, W. (2015). The whole school, whole community, while child model: A new approach for improving educational attainment and healthy development for students. Journal of School Heath, 85(11), 729-739.

Linn, R., Baker, E., \& Betebenner, D. (2002). Accountability Systems: Implications of Requirements of the No Child Left Behind Act of 2001. Educational Researcher, 31(6), 3-16.

Madrigal, S., \& Winner, M.G. (2008). Superflex: A superhero social thinking curriculum. Santa Clara, CA: Think Social Publishing. 
Meiklejohn, J., Phillips, C., Freedman, M. L., Griffin, M. L., Biegel, G., Roach, A., et al. (2012). Integrating mindfulness training into K-12 education: Fostering the resilience of teachers and students. Mindfulness, 3(4).

Merikangas, K. R., Jian-ping, H., Burstein, M., Swanson, S. A., Avenevoli, S., Lihong, C., et al. (2010). Lifetime Prevalence of Mental Disorders in U.S. Adolescents: Results from the National Comorbidity Survey Replication-Adolescent Supplement (NCS-A). Journal of The American Academy of Child \& Adolescent Psychiatry, 49(10), 980-989.

Miles, M. B., Huberman, A. M., \& Saldaña, J. (2014). Qualitative data analysis: A methods sourcebook, 3rd Edition. Washington, DC: Sage Publications.

Napoli, M., Krech, P. R., \& Holley, L. C. (2005). Mindfulness training for elementary school students: The attention academy. Journal of Applied School Psychology, 21, 99-125.

Noble, H., \& Smith, J. (2015). Research made simple: Issues of validity and reliability in qualitative research. Evidence-Based Nursing, 18(2), 34-35.

Patton, M. Q. (2015). Qualitative research and evaluation methods (4th ed.). Thousand Oaks, CA: Sage.

Rempel, K. D. (2012). Mindfulness for children and youth: A review of the literature with an argument for school-based implementation. Canadian Journal of Counseling and Psychotherapy, 46(3), 201-220.

Richards, J. (2012). Teacher stress and coping strategies: A national snapshot. The Educational Forum, 76(3), 299-316.

Schonert-Reichl, K. A., Oberie, E., Stewart Lawlor, M., Abbott, D., Thomson, K., Oberlander, T. F., et al. (2015). Enhancing cognitive and social-emotional development through a simple-to-administer mindfulness-based school program for elementary school children: A randomized controlled trial. Developmental Psychology, 51(1), 52-66. doi:10.1037/a0038454

Sibinga, E. M., Kerrigan, D., Stewart, M., Johnson, K., Magyari, T., \& Ellen, J. M. (2011). Mindfulnessbased stress reduction for urban youth. Journal of Alternative and Complementary Medicine, 17(3), 213218. doi:10.1089/acm.2009.0605

Singh, N. N., Lancioni, G. E., Karazsia, B. T., Felver, J. C., Meyers, R. E., \& Nugent, K. (2016). Effects of Smatha meditation on active academic engagement and math performance of students with attention deficit/hyperactivity disorder. Mindfulness, 7(1) 68-75. doi:10.1007/s12671-015-0424-5

Yin, R. K. (2009). Case study research: Design and methods (2nd ed.). Thousand Oaks, CA: Sage.

Yin, R. K. (2011). Qualitative research from start to finish. New York: Guilford Press. 


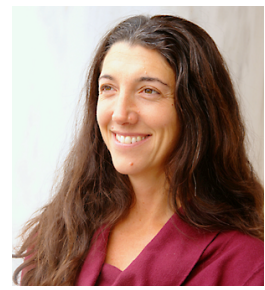

Shana Haines is an Assistant Professor of Education at the University of Vermont. Her research focuses on family-professional partnership, educational experiences of refugee students in American schools, inclusive school reform, and teacher preparation. Shana has published in a variety of journals, including Exceptional Children, Inclusion, Research and Practice for Persons With Severe Disabilities, and Preventing School Failure.

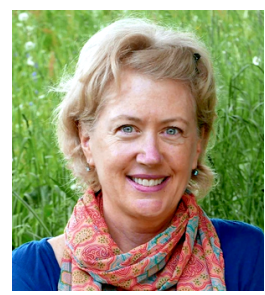

Kelly Clark/Keefe is an Associate Professor at the University of Vermont. Kelly's research brings material feminist and posthumanist theories of affect, art, and identity to bear on a range of overlapping topics including: the physicality of educational subjectivity, stratified versions of schooling, and conceptual analyses of educational leadership. Kelly's work also engages philosophies of poeisis, affect, and habit to argue the usefulness of embodied, arts-informed approaches for researching the complexities of contemporary educational circumstances. Kelly is the author of the book, Invoking Mnemosyne: Art, Memory and the Uncertain Emergence of a Feminist Embodied Methodology (2010).

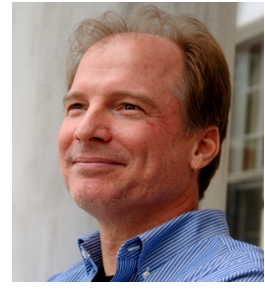

Alan Tinkler is an Assistant Professor of Education at the University of Vermont. His research focuses on community-engaged learning, including service-learning, as a way to support the remodeling of education. He is also interested in other high impact practices, including internships. He has recently joined the internship committee of the Shepherd Higher Education Consortium on Poverty, a consortium that supports funded, eight-week summer internships for students.

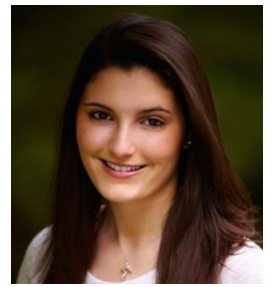

Alyssa Kotsiopoulos is a dual-certified Special Educator teaching at the Kindergarten level in Vermont. Her research interests include understanding the impact of poverty on student development, the relationship between parent involvement and student academic achievement, and effective social-emotional interventions for at-risk students. Alyssa's professional teaching interests center on social justice education and effective inclusion of students with exceptionalities in the general education classroom through differentiated instruction. 


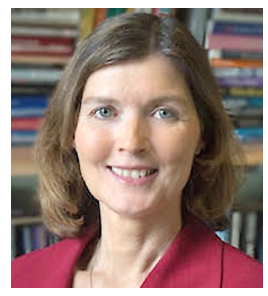

Cynthia Gerstl-Pepin is a Professor of Educational Leadership \& Policy Studies at the University of Vermont. Her research utilizes critical perspectives to examine educational politics and ethical leadership, particularly the media's role in shaping the public's understanding of educational issues and the need for reform. She served as a Fulbright Scholar at Beijing Normal University in the People's Republic of China in 2010. Her most recent work is a co-edited book entitled Reimagining the Public Intellectual in Education: Making Scholarship Matter. Gerstl-Pepin has been published in numerous journals including the Review of Higher Education, Educational Policy, and Teachers College Record.



Katharine G. Shepherd is a Green and Gold Professor in the College of Education and Social Services at the University of Vermont. She teaches undergraduate and graduate courses in special education and leadership, and conducts research focused on collaboration and leadership development for families of children with disabilities, preparation of teachers and leaders for inclusive schools, inclusive school systems, and collaborative data-based decision-making. Dr. Shepherd has served as principal investigator or co-principal investigator for federal and foundation grants totaling over \$3 million. In 2013, she received UVM's Kroepsch-Maurice Award for Excellence in Teaching at the associate professor level.

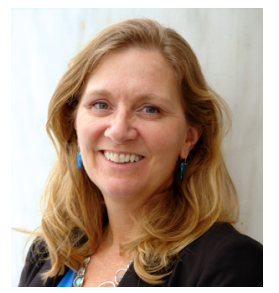

Haley Woodside-Jiron is Associate Professor in the College of Education and Social Services at the University of Vermont. Her interdisciplinary research focuses on the neuroscience of education, how chronic stress and trauma affect learning and development, and school change. She teaches undergraduate and graduate courses in child development, brain research and learning theory, and critical literacy. Dr. Woodside-Jiron currently Chairs the Social Emotional Learning Special Interest Group for the American Education Research Association and has published in a variety of journals including Educational Researcher, Equity \& Excellence in Education, International Journal of Disability, Development and Education, and Reading Research Quarterly.

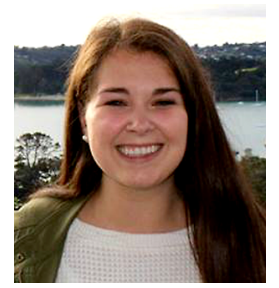

Morgan Milhomens is a senior studying Elementary and Special Education at the University of Vermont. Growing up she dreamed of becoming an elementary school teacher and is currently working hard to achieve that goal. Mindfulness became a personal interest of hers in high school, and she continues to practice mindfulness as a part of daily life through meditative and yoga practice. 